\title{
Performance Study on Solar Hybrid Air- Conditioning System for Residential Water Heating
}

\author{
Kaidir $^{1, *}$, Mulyanef ${ }^{1}$ and Burmawi ${ }^{1}$ \\ ${ }^{1}$ Department of Mechanical Engineering, Bung Hatta University, Padang, Indonesia
}

\begin{abstract}
The Government of Indonesia has done some efforts to overcome energy crisis nationwide. Among them by issuing a policy as the Foundation for the development and improvement of the capacity of providing energy. The Government has issued a presidential instruction number 10 of the year 2005 on energy savings and last Presidential Instruction No. 2 of the year 2008 about saving energy and water. One of the implementation efforts of this energy crisis is overcome with effort saves energy consumption on the air conditioning with develop hybrids air conditioning, namely as the air conditioner at the same time to the water heating. This research is a new technology for energy saving of electricity. The purpose of this research is to produce a prototype of a hybrid energy efficient refrigeration machine that can be function simultaneously as the engine room air conditioner at the same time water heaters. Specific research targets to be achieved is the realization of a prototype of a hybrid air conditioning engine capacity 1.5 PK which can save energy around $60 \%$. The method of research is the planning, creation, testing the performance of air conditioning machines of compression cycle steam hybrid.
\end{abstract}

\section{Introduction}

Hot water can be produced by using the waste heat from an air conditioner. In the places with a year round air conditioning requirement, the heat rejected in the condenser is waste, unless the heat is recovered by using a heat exchanger. This can contributed to energy conservation, and be economically viable. The use of a desuperheater for heating water deserves more attention in the ASEAN countries than in places where there is winter, because a desuperheater does not recover waste heat in winter, but rather uses the energy intend for heating. Normally, heating and cooling systems are widely used in comfort air conditioner and industrial applications. However, the share of the energy for heating and cooling purposes in total energy consumption increases. Due to the economic benefits resulting from high coefficient of performance (COP) values, mechanical heat pump systems become convenient devices for heating and cooling purposes [1], [2]. Heat pump is an apparatus or machine that moves heat from the heat source at a lower temperature to the heat sink at a higher temperature by means of mechanical work or a high temperature heat source [3]. The difference between a conventional a conditioner and a heat pump

\footnotetext{
*Corresponding author: irkaidir@bunghatta.ac.id
} 
is that a heat pump can be used to provide heating or cooling. However, heat pump is still uses the same basic refrigeration cycle for working. It can be easier to say that a heat pump can change which coil is the condenser and which the evaporator by using a reversing valve. So, in cooling conditions, it is common to require heat pumps that are designed only to provide heating. Now a day, the cost of energy continues to rise and it becomes an imperative to save energy and improve overall energy efficiency. A key idea for improving the energy efficiency of many industries is to recover every possible sources of waste heat and convert this energy to a useful output [4]. Moreover, many efforts tried to increase the heat pump performance. However, this study is aimed to investigate the hot water making potential by using the waste heat that released from condenser of the air conditioner. The advantages of this system are as follows: 1) Save energy due to use of the waste heat to produce hot water 2) Without electric short circuit and 3) Fast to produce hot water and 4) Reduce greenhouse gases [5]. So, some recent researches focused on this area are summarized as follows: Roongutai et al. [6] studied the warm water making from air-conditioning system by using of the waste heat that released from the air conditioner. A pressure switch was used to activate both of the condensers, which are automatically controlled. Their results indicated that the highest temperature of the water in the reservoir is $49^{\circ} \mathrm{C}$. Saisanit et al. [7] design and construct the prototype of the hot water making machine using waste heat released from a common air conditioner system.

Two types of the hot water system such as "submerged coil" and "flow through" are used in their study. Solenoid valves were used to control the flow direction of the refrigerant. Air conditioner with cooling capacity of 3,51 KW and working with R-22 was used in this study. The result indicated that the hot water making machine with submerged coil type is more appropriate to use than the flow through type. As mentioned before, the purposes of this study are to investigate the potential of hot water making by using a conventional air conditioner as an air-water heat pump and then to compare the COP of the system between conventional air conditioner cycle and heat pump cycle. The energy saving potential for making of $120 \mathrm{~L}$ hot water is also presented.

Some work on the use of a heat exchanger for domestic water heating has been investigated by a number of authors Xingxing Zhang et al [8], however, are interested in characterization of a solar photovoltaic/loop-heat-pipe heat pump water heating system. Wonseok Kim et al [9], performance analysis of hybrid solar-geothermal CO2 heat pump system for residential heating were tested

Pradeep Bansal et al [10] Status of not-in-kind refrigeration technologies for household space conditioning, water heating and food refrigeration. Boonrit Prasartkaew et al [11] interested in a study of the Experimental study on the performance of a solar-biomass hybrid air conditioning system. Anjali at al [12] studied the performance analysis of a solar hybrid air conditioner with waste heat recovery and re-use using evacuated tube collector. Aziz et al [13] studied the potential use of heat energy wasted in condenser ac central for water heating to save energy.

\section{Experimental Apparatus}

A Panasonic Eco smart Under-Ceiling split room air - conditioner had a rated capacity of $3.51 \mathrm{~kW}(12,000 \mathrm{Btu} / \mathrm{h})$. The air conditioner had a hermetic type compressor and a thermostatic expansion device. A Helix heat exchanger was installed between its compressor discharge and condenser inlet. A schematic of the system is shown in Figure 1. The hot water storage tank had a capacity of 120 liters, and was located beside the air-conditioner. The system was tested in Machine Performance of room, which was at $27^{\circ} \mathrm{C}$. During the test, no hot water was consumed, and the water temperature in the storage tank increased from $27^{\circ}$ $\mathrm{C}$ to $62.1^{\mathrm{O}} \mathrm{C}$ in 240 minutes. Consider the simple vapor-compression refrigeration cycle that forms part of an air conditioning plants as shown schematically in Figure 1. 


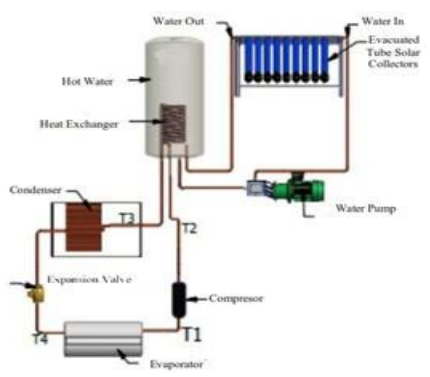

Fig. 1. Schematic of a hybrid air-conditioner

\section{Energy Consideration}

In order to study the hot water making potential of the air conditioning system and then compare of the COP between common cycle and air conditioning cycle, the important parameters can be calculated from following equation.

Cooling capacity at evaporator $\left(\mathrm{Q}_{\text {Evap }}\right)$

$$
\mathrm{Q}_{\text {Evap }}=\mathrm{Q}_{\mathrm{e}} / \dot{\mathrm{m}} \mathrm{r}=\mathrm{h}_{1}-\mathrm{h}_{4}
$$

Compressor work (WComp)

$$
\mathrm{W}_{\text {Comp }}=\mathrm{wc} / \dot{\mathrm{m} r}=\mathrm{h}_{2}-\mathrm{h}_{1}
$$

Heating Capacity at Condensor, $\left(\mathrm{Q}_{\text {Cond }}\right)$

$$
\mathrm{Q}_{\text {Cond }}=\mathrm{Qk} / \dot{\mathrm{m}} \mathrm{r}=\mathrm{h}_{2}-\mathrm{h}_{3}
$$

Coefficient of performance $\left(\mathrm{COP}_{\mathrm{A}}\right)$

$$
\mathrm{COP}_{\mathrm{A}}=\mathrm{Q}_{\mathrm{COn}} / \mathrm{W}_{\mathrm{Comp}}
$$

Coefficient of performance Carnot $\left(\mathrm{COP}_{\mathrm{C}}\right)$

$$
\left(\mathrm{COP}_{\mathrm{C}}\right)=\mathrm{T}_{\text {Cond }} /\left(\mathrm{T}_{\mathrm{Cond}}-\mathrm{T}_{\mathrm{Eva}}\right)
$$

Coefficient of performance Refrigeration, $\left(\mathrm{COP}_{\mathrm{Ref}}\right)$

$$
\mathrm{COP}_{\mathrm{Ref}}=\left(\mathrm{h}_{1}-\mathrm{H}_{4}\right) /\left(\mathrm{h}_{2}-\mathrm{h}_{1}\right)
$$

Coefficient of performance Hybrid, $\left(\mathrm{COP}_{\mathrm{Hyb}}\right)$

$$
\mathrm{COP}_{\mathrm{Hyb}}=\left(\mathrm{Q}_{\text {kond }}+\mathrm{Q}_{\mathrm{eva}}\right) / \mathrm{W}_{\text {comp }}
$$

\section{Result and Discussion}

Figure 4.1 shows that the air humidity level of an average of 75.1 percent at the beginning of the air conditioning is operated by room air humidity $90.5 \%$ within 120 minutes of operation there is a decrease in air humidity of $22.5 \%$ so that air humidity reaches $68 \%$. The initial temperature of the conditioned room was $26.5^{\circ} \mathrm{C}$ after operating for 120 minutes with a temperature drop of $8{ }^{\circ} \mathrm{C}$ resulting in a temperature of $18.5{ }^{\circ} \mathrm{C}$. Voltage electrical energy is a constant 220 volt compressor and a large amperage of electrical energy used for hybrid air refrigeration machines 
constant 5 amperes. The initial temperature in a tank with a capacity of 100 liters is $27.5{ }^{\circ} \mathrm{C}$, within 120 minutes the temperature of hot water reaches $45.7^{\circ} \mathrm{C}$.

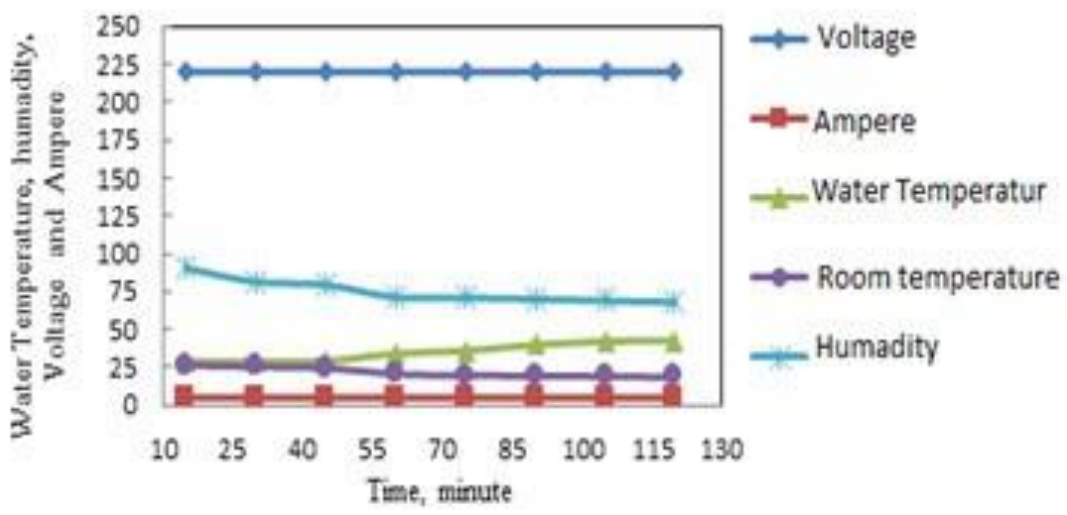

Fig. 4.1 Temperature, Voltage, Amphere vs Time Operation Hybrid Air Conditioning

The variation in the capacity of hot air in the tank which results in the operation of the hybrid air conditioning machine (hybrid AC) within 120 minutes is shown in Figure 4.2 below. The air variation in the tank starts from 20 liters, 35 liters, 40 liters, 50 liters, 60 liters, 70 liters, 85 liters to a maximum of 100 liters of air. The maximum temperature of water produced in the tank is $55.5 \mathrm{OC}$ at a 50 liter tank capacity. In the research of air conditioning machines carried out for 6 hours, the maximum temperature of hot air obtained reached 88.5 OC.

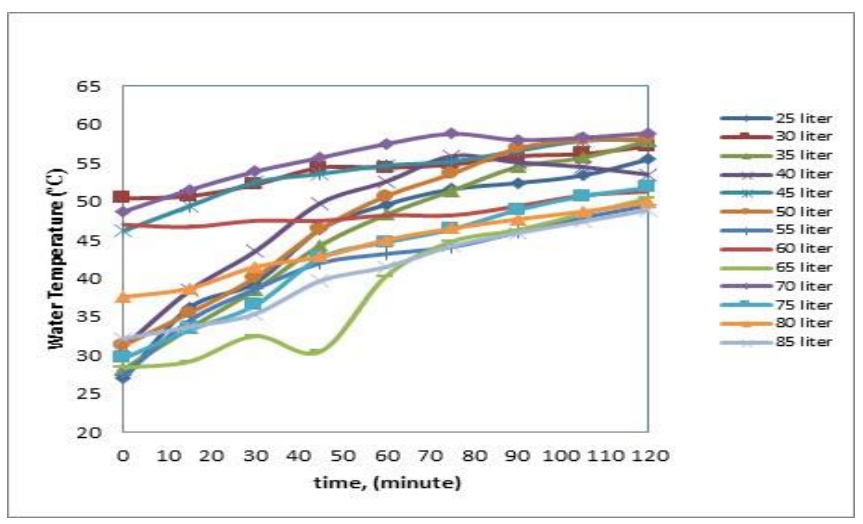

Fig. 4.2 Water Temperature, OC vs Time Operation Hybrid Air Conditioning

\section{Conclusion}

Hybrid vapor compression air conditioning machines as air conditioners for residential buildings or hotels can be used to produce water for bathing and washing purposes. In this research, the refrigerant used as working fluid R22. In this study using a standard air conditioning machine with a capacity of 12000 BTU, this refrigeration machine was modified by adding a heat exchanger unit. This heat exchanger is installed between the compressor and condenser. Exchanges planned and made are spring shaped helic heat exchangers made from quarter inch copper pipe material. The results of the research that have been done are obtained by the hybridization engine perfusion coefficient, as follows, the average value of the actual hybrid air refraction engine coefficient of performance $(\mathrm{COP})_{\mathrm{A}}=3.35$. Average Rankine hybrid air 
refraction (COP) machine performance coefficient value $\mathrm{R}=8.46$. And the average value of the Carnot hybrid air refraction machine (COP) $\mathrm{C}$ performance coefficient $=9.85$.

The production of hot water using heat from refrigerant heat out the compressor of the air conditioning hybrid engine studied produces hot water with water capacities varying from 20 liters to 100 liters. For the operating time of the hybrid refrigeration machine for 120 minutes, the temperature of hot water was $55.5^{\circ} \mathrm{C}$. At a tank capacity of 100 liters of water with the operating time of the air conditioning machine for 6 hours the maximum hot water temperature is $88.5^{\circ} \mathrm{C}$.

I would like to thank Directorate General of Higher, Ministery Research and Higher Education, Republic of Indonesia, DIPA 2017 DIPA- 042.01.1.655462/2017

\section{References}

1. Ulku, S., Adsorption heat pumps. Heat Recovery System, pp. 277-284, (1986)

2. Ulku, S., The Netherlands: Martinus Nijkoff Publishers, 1987 Systems and Equipment volume of the ASHRAE Handbook, ASHRAE, Inc., Atlanta, GA, (2004)

3. Chua, K.J., Chou, S.K. and Yang, W.M., Applied Eergy,. 87, 3611-3624, (2010)

4. Roongutai, P., Sangsuwan, S., Channaen, S. and Lakchan, A., King Mongkut's University of Technology, (1999)

5. Saisanit, P., PattanaIm, N., Hachanont, P., and Chanpueng, W., Research report at Rajamangala University of Technology Thanyaburi, (2008).

6. Saisanit, P., PattanaIm, N., Hachanont, P., and Chanpueng, W., Research report at Rajamangala University of Technology Thanyaburi, (2008).

7. Zhang.X., Zhao.X .,Xu.J., and Yu.X,, Applied Energy 102, 1229- 1245, (2013)

8. Kim.W, Choi.J, and Cho.H,, Renewable Energy 50 596-604, (2013).

9. Bansal.P, Vineyard.E, and Abdelaziz.O, International Journal of Sustainable Built Environment 1, 85-101, (2012)

10. Prasartkaewa.B, S. Kumar B., Renewable Energy 57 86-93. (2013)

11. S. Nithya, Lalitha Shree, Kiruthika and Krishnaveni, International Journal of Electronics and Communication Engineering and Technology, 8(2)75-80. (2017)

12. Aruna. S. Ningade and Rudranna Nandihalli, International Journal of Electrical Engineering \& Technology (IJEET), 5 191-198 (2014) 